\title{
Selection of Models for Ingestion Pathway and Relocation
}

by

A. Blanchard

Westinghouse Savannah River Company

Savannah River Site

Aiken, South Carolina 29808

J. M. Thompson

WSMS

DOE Contract No. DE-AC09-96SR18500

This paper was prepared in connection with work done under the above contract number with the U.S.

Department of Energy. By acceptance of this paper, the publisher and/or recipient acknowledges the U.S. Government's right to retain a nonexclusive, royalty-free license in and to any copyright covering this paper, along with the right to reproduce and to authorize others to reproduce all or part of the copyrighted paper. 
Keywords: Ingestion Emergency Planning Dispersion Model

Retention: Lifetime

\section{Selection of Models for Ingestion Pathway and Relocation (U)}

November 1998

\section{Classification}

\section{UNCLASSIFIED}

DOES NOT CONTAIN

UNCLASSIFIED CONTROLLED

NUCLEAR INFORMATION

ADC \&

Reviewing

Official:

Steven J. Nathan, Principal Engineer

Date: $11 / 24 / 98$

Westinghouse Savannah River Company Project Engineering \& Construction Division Aiken, SC 29808

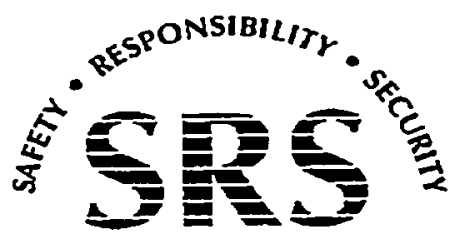

SAVANNAH RIVER SITE

PREPARED FOR THE U.S. DEPARTMENT OF ENERGY UNDER CONTRACT NO. DE-AC09-96SR18500 


\section{Selection of Models for Ingestion Pathway and Relocation (U)}

Jay M. Thompson

November 1998

Westinghouse Savannah River Company Project Engineering \& Construction Division Aiken, SC 29808

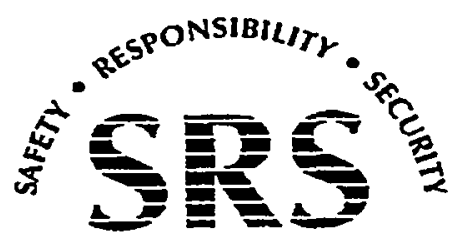

SAVANNAH RIVER SITE

PREPARED FOR THE U.S. DEPARTMENT OF ENERGY UNDER CONTRACT NO. DE-AC09-96SR18500 


\section{DISCLAIMER}

This report was prepared as an account of work sponsored by an agency of the United States Government. Neither the United States Government nor any agency thereof, nor any of their employees, makes any warranty, express or implied, or assumes any legal liability or responsibility for the accuracy, completeness, or usefulness of any information, apparatus, product, or process disclosed, or represents that its use would not infringe privately owned rights. Reference herein to any specific commercial product, process, or service by trade name, trademark, manufacturer, or otherwise does not necessarily constitute or imply its endorsement, recommendation, or favoring by the United States Government or any agency thereof. The views and opinions of authors expressed herein do not necessarily state or reflect those of the United States Government or any agency thereof.

This report has been reproduced directly from the best available copy.

Available to DOE and DOE contractors from the Office of Scientific and Technical Information, P.O. Box 62, Oak Ridge, TN 37831; prices available from (615) 576-8401.

Available to the public from the National Technical Information Service, U.S. Department of Commerce, 5285 Port Royal Road, Springfield, VA 22161. 


\section{DISCLAIMER}

Portions of this document may be illegible in electronic image products. Images are produced from the best available original document. 
PROJECT: $\quad$ N/A

DOCUMENT: $\quad$ WSRC-TR-98-00392

TITLE:

Selection of Models for Ingestion Pathway and Relocation (U)

REVISION NUMBER: $\quad 1$

AUTHOR/TECHNICAL REVIEWS:

Am Thtompen

$\mathrm{J} / \mathrm{M}$. Thompson/Author

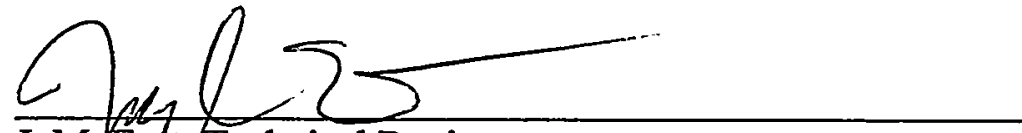

J. M. East.Technical Reviewer

Eni arkl

K. R. O’Kula, Technical Reviewer $\frac{11 / 24 / 98}{\text { Date }}$

$\frac{11 / 24 / 1228}{\text { Date }}$

$\frac{11-24-98}{\text { Date }}$

\section{APPROVALS:}

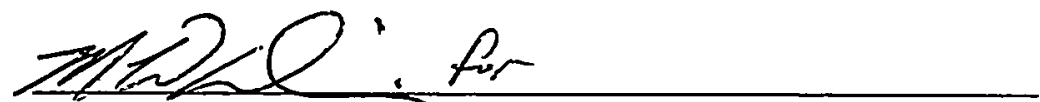

C. E. Shogren, Manager ESTG

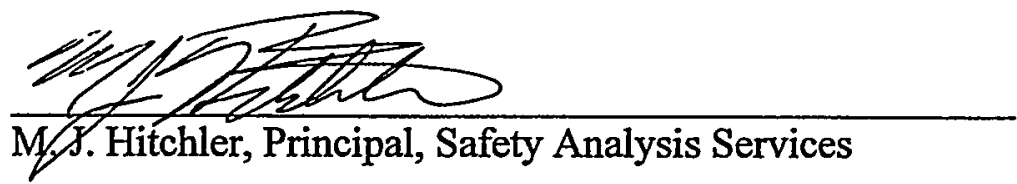

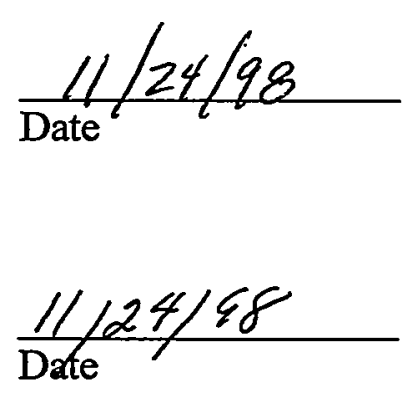




\begin{abstract}
The area in which intermediate phase protective actions (such as food interdiction and relocation) may be needed following postulated accidents at three Savannah River Site nonreactor nuclear facilities will be determined by modeling. The criteria used to select dispersion/deposition models are presented. Several models are considered, including ARAC, MACCS, HOTSPOT, WINDS (coupled with PUFF-PLUME), and UFOTRI. Although ARAC and WINDS are expected to provide more accurate modeling of atmospheric transport following an actual release, analyses consistent with regulatory guidance for planning purposes may be accomplished with comparatively simple dispersion models such as HOTSPOT and UFOTRI. A recommendation is made to use HOTSPOT for non-tritium facilities and UFOTRI for tritium facilities. The most recent Food and Drug Administration Derived Intervention Levels (August 1998) are adopted as evaluation guidelines for ingestion pathways.
\end{abstract}




\section{CONTENTS}

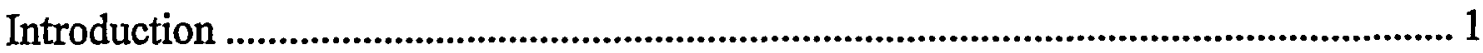

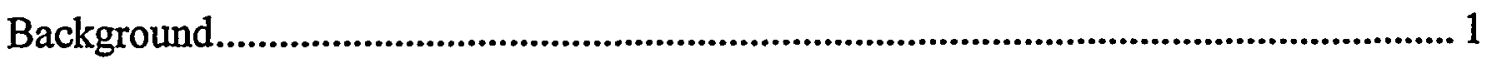

Approach ................................................................................................................... 1

Selection Criteria ...................................................................................................... 3

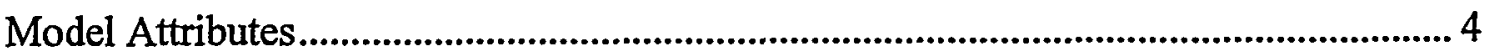

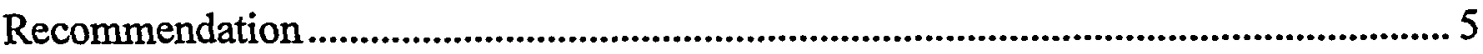

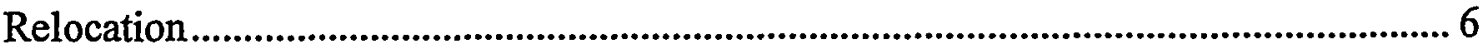

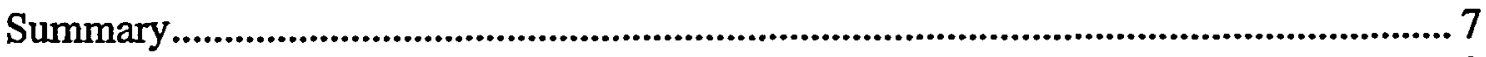

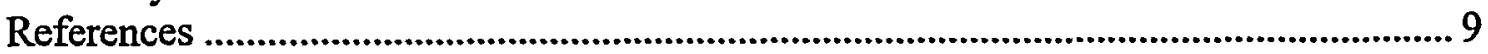

\section{TABLES}

Table 1: Illustrative pathway for internal radiation exposure from airborne radionuclide

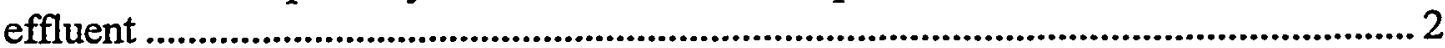

Table 2: Recommended modeling of pathway steps ........................................................... 7 


\section{SELECTION OF MODELS FOR INGESTION PATHWAY AND RELOCATION (U)}

\section{Introduction}

At the request of the States of South Carolina and Georgia, releases from postulated severe accidents at three nonreactor nuclear facilities at the Savannah River Site (SRS) will be evaluated to determine the potential impacts on ingestion planning activities. Evaluation of postulated releases, in a manner consistent with that used by the Nuclear Regulatory Commission (NRC) in NUREG-0396 (NRC 1978) and NUREG-0654 (NRC 1980), will provide a perspective on the potential consequences that accidents at existing and operating nonreactor nuclear facilities may have on ingestion pathways. Similarly, determining where relocation protective action guidelines are exceeded will provide a perspective on potential long-term consequences.

\section{Background}

Following discussions with the States of South Carolina and Georgia, initiators will be selected from severe accident scenarios documented as part of the existing Emergency Preparedness Hazards Assessments for three SRS facilities. The facilities chosen for analysis (to be performed in early 1999) are the Tritium Facilities, H-Canyon, and the Savannah River Technology Center (SRTC). These three facilities provide a good representation of the radionuclides of interest at SRS.

Analyses will be performed for all significant radionuclides in the accident source term mixes (i.e., equivalent plutonium will not be used). Radionuclide-specific values are necessary since pathway transfer factors vary for different elements, and dose values for ingestion may not scale with inhalation dose values.

\section{Approach}

The overall approach proposed to evaluate the impact on the food chain may be divided into several steps that follow radioactive material through the environment and food chain to man. Table 1 was adapted from NCRP-50, Environmental Radiation Measurements (NCRP 1976). This table illustrates the steps from release of radionuclides into the environment to the dose that results from ingestion by man.

The first pathway step describes the amount of material released to the environment. As mentioned previously, source terms from severe accidents at three facilities will be chosen. Tritium releases will be modeled as gas or water vapor. Releases from nontritium facilities will be modeled as particulates. 
Table 1: Illustrative pathway for internal radiation exposure from airborne radionuclide effluent

\begin{tabular}{|c|c|c|}
\hline Pathway Step & Variable & Product of Variables \\
\hline Source & Source term (Q) & $\begin{array}{l}\text { Radioactive material released }(\mathrm{Bq}) \\
\mathrm{Q}\end{array}$ \\
\hline Dispersion & Dispersion $(\chi / Q)$ & 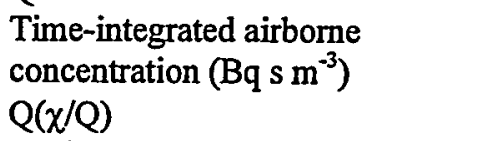 \\
\hline Cumulative Deposition & Deposition velocity $\left(V_{d}\right)$ & 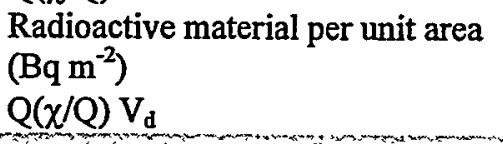 \\
\hline $\begin{array}{l}\text { Environmental and Biological } \\
\text { Transfer }\end{array}$ & Transfer coefficient $\left(T_{r}\right)$ & $\begin{array}{l}\text { Radioactive material per unit } \\
\text { mass of environmental or } \\
\text { biological medium }\left(\mathrm{Bq} \mathrm{kg}^{-1}\right) \\
\mathrm{Q}(\mathrm{x} / \mathrm{Q}) \mathrm{V}_{\mathrm{d}} \mathrm{T}_{\mathrm{r}}\end{array}$ \\
\hline (C) (C) & Gatison basis concentration & food) \\
\hline Human Intake & Intake rate (I) & $\begin{array}{l}\text { Radioactive material intake per } \\
\text { unit time }\left(B q ~^{-1}\right) \\
Q(\chi / Q) V_{d} T_{r} I\end{array}$ \\
\hline Human Absorbed Dose Rate & $\begin{array}{l}\text { Intake rate to absorbed dose rate } \\
\text { conversion factor }(\mathrm{k})\end{array}$ & $\begin{array}{l}\text { Absorbed dose per unit time } \\
\left(\mathrm{rad} \mathrm{s}^{-1}\right) \\
\mathrm{Q}(\mathrm{\chi} / \mathrm{Q}) \mathrm{V}_{\mathrm{d}} \mathrm{T}_{\mathrm{r}} \mathrm{lk}\end{array}$ \\
\hline
\end{tabular}

The dispersion pathway step transports the release to locations of interest. The cumulative deposition pathway step quantifies the amount of contaminant deposited on the ground (or directly on the foodstuff in some cases). Further discussion of models for the dispersion and deposition pathway steps are discussed in the "Selection Criteria" and later sections.

Environmental and biological transfer coefficients relate the concentration of radionuclides in one compartment of the pathway to another. For example, radionuclides may be transferred from the compartment "pasture" to the compartment "milk". Although in Table 1 only one transfer coefficient value is shown $\left(T_{r}\right)$, radioactive contaminants may pass through multiple compartments to reach man. Each compartment would be described by a separate coefficient, and the overall value obtained by taking the product of the coefficients from each compartment. When available, site-specific transfer coefficients will be used. Otherwise, default values derived from Regulatory Guide 1.109 (NRC 1977a), or more recent publications (e.g., IAEA Technical Reports Series No. 364, Handbook of Parameter Values for the Prediction of Radionuclide Transfer in Temperate Environments (IAEA 1994) or Radiological Assessment (Till and Meyer 1983)) are recommended. 
The product of variables after applying environmental and biological transfer factors (the radioactive material per unit mass of environmental or biological medium) may be compared to Derived Intervention Levels (DILs) in recent Food and Drug Administration (FDA) guidance (FDA 1998). The intake rate and dose rate conversion factor in the last two rows of Table 1 are incorporated in the derivation of the DIL for each group of nuclides.

Notwithstanding the most recent FDA guidance, it must be recognized that current DOE guidance in DOE G 151.1-1, Vol. 2, Section B.2.1, Radiological Protective Action Criteria (DOE 1997) recommends the use of the old FDA guidance. Since the new FDA guidelines were issued recently, it is presumed that DOE guidance will be revised to reference the new guidelines. The new FDA guidelines appear to be much more restrictive than the old guidelines. Therefore, the new FDA DILs are recommended for use as evaluation guidelines for the ingestion pathways.

Relatively simple dispersion/deposition codes may be used to calculate the impacts from releases. A deposition level, equivalent to the DIL for each pathway, may be derived by applying environmental and biological transfer factors to each DIL. Calculation of deposition levels that are equivalent to DILs may be performed using a spreadsheet. A dispersion/deposition code can then be used to determine the area within which each limiting deposition value is exceeded.

Considerations for selecting a dispersion/deposition model follow.

\section{Selection Criteria}

Several technical factors enter into the selection of atmospheric dispersion models. The selected model(s) should be fundamentally equivalent to models used for similar purposes at commercial reactors. For accidents releasing a mix of radionuclides, the input routines should have the capability to run a mix of nuclides. Additionally, the model should be among, or be consistent with, those models that will actually be used or available following a release. The model should allow the user to modify dispersion and deposition parameters to site-specific values. It should also have adequate documentation.

If several models are found that meet the technical factors, preference will be given to the simplest one(s), in accordance with scientific consensus (NCRP 1996). Choosing the least complex model has several advantages. In general, the time needed to construct input files and run a simple model is shorter. Fewer input parameters reduce the likelihood of a transcription error. Additionally, the results from simple models may be more easily verified by hand calculations than those from complex models.

A perspective on the necessary level of complexity in the dispersion/deposition model may be obtained from regulatory documents. NUREG-0396 (NRC 1978), p. I-20, identifies the "simple, theoretical, Gaussian plume model" for performing initial projections of dose during an incident (this is for early phase predictions). For the 
ingestion pathway (intermediate phase), the impacted area (for large commercial reactors) is based on accident analyses assuming worst possible meteorology and a straight-line trajectory (p. I-34). An acceptable method for performing these analyses is found in Regulatory Guide 1.4 (NRC 1974). The model that is recommended in Regulatory Guide 1.4 is the Gaussian plume model. Regulatory Guide 1.109 (NRC 1977a) describes an acceptable method to calculate the annual doses to man from routine releases of reactor effluent. The annual dispersion factor is calculated using a Gaussian model from Regulatory Guide 1.111, (NRC 1977b). Clearly, the Gaussian dispersion model has been accepted by the NRC, and was used as the underlying dispersion model for the determination of preplanned ingestion pathway protective actions. EPA has also issued acceptable methods to evaluate airborne pollutants based on the Gaussian model.

For particulate releases, a Gaussian-based dispersion model, capable of calculating deposition from an acute release, should be adequate. More complex dispersion models could also be used. For tritium releases, a dispersion and tritium absorption code that can model the incorporation of tritium into the food chain from an acute release is desirable.

In addition to the minimum technical capabilities noted above, other factors are important. The model should be available for use by a variety of involved organizations. Preferably, emergency planning/preparedness personnel at the States and SRS are familiar with the chosen model(s). The model should have low costs associated with acquisition, training, and execution.

In summary, the primary selection criteria are:

- acute release modeling capability

- simplicity

- availability

- familiarity

- cost

\section{Model Attributes}

A description of available models is found in Atmospheric Dispersion Modeling Resources (DOE 1995). This document was reviewed, along with additional references such as user's manuals, technical reports, and journal articles. Discussions with some model users were held to ascertain current capabilities.

Several models were considered for determining the consequences of releases from SRS facilities. These included ARAC, MACCS, HOTSPOT, WINDS (coupled with PUFFPLUME), and UFOTRI. Descriptions of the first four models are found in DOE 1995; attributes of the last model, UFOTRI, are summarized in O'Kula et al. 1998. Brief descriptions of these models follow, but the reader is referred to these documents (and associated references) for detailed descriptions. 
ARAC is a particle-in-cell model developed by Lawrence Livermore National Laboratory (LLNL). The particle-in-cell model is more realistic and potentially can address more complex meteorological conditions than Gaussian models. It provides three-dimensional modeling of airborne effluent transport. The underlying dispersion model is more complex than the Gaussian model. Acute releases can be modeled. Access is via a remote terminal back to LLNL, with limited availability at SRS (access would have to be purchased). ARAC plots are familiar to many people at the States and SRS, but detailed operational and code experience are limited. The cost to acquire access to the code, train users, and run the model is relatively high.

MACCS couples a Gaussian dispersion model with advanced pathway and consequence models. It has been used to predict the consequences of postulated severe commercial reactor accidents by the NRC. It is capable of modeling acute releases. Input files are relatively complex. MACCS is available at SRS, but would have to be purchased by the States. Due to the limited distribution and complex input files, fewer people are familiar with MACCS than simpler codes. The complexity of the input files, as well as the format of the output, contribute to a medium cost rating.

HOTSPOT is a simple Gaussian model with acute release modeling capability. HOTSPOT runs on a personal computer and has been acquired by many organizations. Many individuals at the States and SRS are users of HOTSPOT, contributing to a high degree of familiarity. The ease of use, documentation, and user familiarity contribute to its low cost.

WINDS (coupled with PUFF-PLUME) was developed specifically for SRS, and would be used following an actual event to provide rapid estimates of doses from passing clouds. The PUFF-PLUME model basis is Gaussian. WINDS can model acute releases. This model has a moderate level of complexity (commensurate with its real-time capabilities). It is available at SRS but not at the States, although access may be gained off-site via modem. A moderate degree of familiarity and moderate cost to run are associated with this model.

UFOTRI was developed to assess the radiological consequences of accidental atmospheric tritium releases. The dispersion model is Gaussian and can be used to assess acute releases. UFOTRI is moderately complex since tritium-specific processes such as the conversion of tritium gas (HT) into tritiated water (HTO), re-emission after deposition, and conversion of HTO into organically bound tritium (OBT) are modeled (O'Kula et al.998). UFOTRI is available at SRS, but would have to be purchased by the States. A limited number of personnel are familiar with UFOTRI. It is expected that moderate costs will be associated with running UFOTRI.

\section{Recommendation}

The model(s) chosen to estimate the potential consequences from SRS severe accidents should use methodology consistent with EPA guides for protective actions (EPA 1992), Regulatory Guide 1.145 (NRC 1982), NUREG-0654 (NRC 1980), and NUREG-0396 
(NRC 1978). Several models were considered for these analyses. A Gaussian dispersion model would be adequate for the sorts of calculations to be performed. The use of a Gaussian model is also repeated in DOE guidance for emergency planning (DOE 1997):

"The following modeling recommendations are provided as guidance to consequence analysts.

- Use of a straight line Gaussian model as the atmospheric dispersion portion of the code is acceptable in most cases for emergency planning."

Historically, preplanned emergency actions have been based on simple meteorological conditions. Since minimizing code complexity should maximize clarity and economy, HOTSPOT is proposed as the model to be used to perform dispersion and deposition calculations for non-tritium releases. Deposition values resulting in concentrations in food equal to recent FDA DILs may then be calculated in a spreadsheet format. Deposition footprints at which recent FDA DILs are exceeded may be determined using HOTSPOT.

The computer model UFOTRI is proposed for assessment of Tritium Facilities severe accidents. The higher degree of pathway model complexity available in UFOTRI is needed to assess the effects of an acute release of tritium to the environment. The underlying dispersion model is Gaussian, consistent with regulatory recommendations. As an alternative to UFOTRI, HOTSPOT may be used to obtain time-integrated concentrations of tritiated water vapor. Appropriate environmental and biological transfer factors will then be applied in a spreadsheet format to obtain concentrations of tritium in foodstuffs.

\section{Relocation}

The Manual of Protective Action Guides And Protective Actions For Nuclear Incidents (EPA 1992) provides methods to calculate projected external gamma dose and inhalation dose during the intermediate phase of emergency response. Dose conversion factors (mrem received over time periods of interest, per unit deposition or per unit air concentration of resuspended material) are presented for major fission products. These dose conversion factors are based on DOE/EH-0070 (DOE 1988) (external dose) and Federal Guidance Report No. 11 (EPA 1988) (inhalation dose).

EPA 1992 does not provide inhalation dose conversion factors for transuranics. These dose conversion factors may be obtained from Federal Guidance Report No. 11 (EPA 1988), or more current guidance from the International Commission on Radiological Protection (e.g., ICRP 1995). The most current ICRP ingestion dose conversion factors are used by the FDA to calculate DILs for ingestion pathways. Since the most current ICRP guidance represents the state-of-the-art in our understanding of the behavior of radionuclides in the body, and already forms the basis for ingestion pathway interdiction criteria from the FDA, its use as a basis for relocation decisions is recommended. 
However, it must also be recognized that the basis used in most current U.S. and State regulations is ICRP-30 (ICRP 1979). In the event of an actual release, it seems probable that decisions would be based on the best models, incorporating the results of research since ICRP-30 was written. Therefore, inhalation dose conversion factors based on the most recent ICRP publications are proposed as the basis for relocation calculations.

A major parameter for relocation calculations is the resuspension factor. Resuspension factors specific to the SRS area will be selected for dominant radionuclides in each SRS accident scenario. The equivalent effect for tritium, reemission from soil and vegetation, will be modeled using site-specific values, when available.

\section{Summary}

HOTSPOT is recommended for the analysis to determine when intermediate phase actions must be taken for SRTC and H-Canyon severe accidents. For the Tritium Facilities, UFOTRI is recommended. In general, site-specific parameters will be applied when available. Food pathway transfer factors from the most recent ICRP, IAEA, NCRP, and NRC recommendations will be used wherever possible. These factors represent the state-of-the-art in describing the movement of radionuclides through the food chain. Limiting values of cumulative deposition, resulting in concentrations of radionuclides in foodstuffs equivalent to the most recent FDA DILs (FDA 1998), will be derived and used as the basis to determine the area for ingestion pathway protective actions. Similarly, dose from resuspension will be calculated using the most recent inhalation dose factors from ICRP, and site-specific resuspension factors.

Table 2 summarizes the approach that will be taken to sequentially model or determine each pathway step in Table 1 . Site-specific transfer coefficients will be used whenever available.

Table 2: Recommended modeling of pathway steps

\begin{tabular}{lll}
\hline Pathway Step & Model - SRTC and H-Canyon & Model - Tritium Facilities \\
\hline Source & Severe accidents & Severe accidents \\
Dispersion & HOTSPOT & UFOTRI \\
& $95 \%$ worst case meteorology & 95\% worst case meteorology \\
Cumulative Deposition & HOTSPOT and site specific & UFOTRI and site specific \\
& parameters & parameters \\
Environmental and Biological & Site-specific transfer coefficients & Site-specific transfer coefficients \\
Transfer & when available; & when available; \\
& ICRP/IAEA/NCRP/NRC & ICRP/LAEA/NCRP/NRC \\
Human Intake & Implicit in updated FDA Derived & Implicit in updated FDA Derived \\
& Intervention Levels & Intervention Levels \\
Human Absorbed Dose Rate & Implicit in updated FDA Derived & Implicit in updated FDA Derived \\
& Intervention Levels & Intervention Levels \\
\hline
\end{tabular}


Areas exceeding protective action guides for relocation will be determined using the same models used for the ingestion pathway calculations. The most recent inhalation dose factors from ICRP, and site-specific resuspension factors are recommended for use in resuspension calculations. 


\section{References}

Department of Energy. External dose-rate conversion factors for calculation of dose to the public. Washington, DC: DOE; DOE/EH-0070, 1988.

Department of Energy. Atmospheric Dispersion Modeling Resources, Second Edition. Washington, DC: DOE; 1995.

Department of Energy. Emergency management guide-hazards surveys and assessments. Washington, DC: DOE; DOE G 151.1-1 Vol. 2, 1997.

Environmental Protection Agency. Limiting values of radionuclide intake and air concentration and dose conversion factors for inhalation, submersion, and ingestion. Washington, DC: EPA; Federal Guidance Report No. 11, EPA 520/1-88-020, 1988.

Environmental Protection Agency. Manual of protective action guides and protective actions for nuclear incidents. Washington, DC: EPA; EPA 400-R-92-001, 1992.

Food and Drug Administration. Accidental contamination of human foods and animal feeds: recommendations for state and local agencies. Rockville, MD: FDA; August $13,1998$.

International Atomic Energy Agency 1994, Handbook of parameter values for the prediction of radionuclide transfer in temperate environments. Vienna: IAEA; Technical Reports Series No. 364; 1994.

International Commission on Radiological Protection. Limits for intake by workers. Oxford: Pergamon Press; ICRP Publication 30, Annals of the ICRP Vol. 3, No. 1-4; 1979.

International Commission on Radiological Protection. Age-dependent doses to members of the public from intake of radionuclides: part 5 compilation of ingestion and inhalation dose coefficients. Oxford: Pergamon Press; ICRP Publication 72, Annals of the ICRP Vol. 26, No. 1; 1995.

National Council on Radiation Protection and Measurements. Environmental radiation measurements. Bethesda, MD: NCRP; NCRP Report No. 50; 1976.

National Council on Radiation Protection and Measurements. Screening models for releases of radionuclides to atmosphere, surface water, and ground. Bethesda, MD: NCRP; NCRP Report No. 123 I; 1996.

Nuclear Regulatory Commission. Assumptions used for evaluating the potential radiological consequences of a loss of coolant accident for pressurized water reactors. Washington, DC: NRC; Regulatory Guide 1.4, Rev. 2; 1974. 
Nuclear Regulatory Commission. Calculation of annual doses to man from routine releases of reactor effluents for the purpose of evaluating compliance with $10 \mathrm{CFR}$ Part 50, Appendix I. Washington, DC: NRC; Regulatory Guide 1.109, Rev. 1; 1977a.

Nuclear Regulatory Commission. Methods for estimating atmospheric transport and dispersion of gaseous effluents in routine releases from light-water-cooled reactors. Washington, DC: NRC; Regulatory Guide 1.111; $1977 \mathrm{~b}$.

Nuclear Regulatory Commission. Planning basis for the development of state and local government radiological emergency response plans in support of light water nuclear power plants. Washington, DC: NRC; NUREG-0396/EPA 520/1-78-016; 1978.

Nuclear Regulatory Commission. Criteria for preparation and evaluation of radiological emergency response plans and preparedness in support of nuclear power plants. Washington, DC: NRC; NUREG-0654/FEMA-REP-1, Rev. 1; 1980.

Nuclear Regulatory Commission. Atmospheric dispersion models for potential accident consequence assessments at nuclear power plants. Washington, DC: NRC; Regulatory Guide 1.145, Rev. 1; 1982.

O'Kula, K. R.; East, J. M.; Murphy, Jr., C. E. Evaluating postulated tritium releases on a large DOE site using the UFOTRI probabilistic consequence model (U). In: Proceedings of the $4^{\text {th }}$ International Conference on Probabilistic Safety Assessment and Management; 1998.

Till, J.; Meyer, H. Radiological assessment. Washington, DC: NRC; NUREG/CR3332/ORNL-5968; 1983. 